\title{
Impact of Deterrents on Effectiveness of Mandatory Continuing Professional Education for Company Secretaries in India
}

\author{
Rajesh Walawalkar
}

Academy of Human Resource Development, India

Copyright $(\underset{0}{2015}$ Horizon Research Publishing All rights reserved.

\begin{abstract}
This study is about the perceptions of Company Secretaries about effectiveness of their formal and mandatory Continuing Professional Education (CPE) programme run by the Institute of Company Secretaries of India. The objectives were to ascertain: 1 . to what extent do Company Secretaries perceive their CPE as effective, 2. what are the various barriers (deterrents) faced by Company Secretaries to participate effectively in CPE, 3. Whether there exist any significant differences in perceptions of Company Secretaries in terms of gender, regions of India, and groups formed by number of years of experience. A self-completion two-part Survey Instrument was developed by the researcher by using focus group method. Research design was dominated by quantitative statistical methods. Data was collected by personally administered method by the researcher himself and analysis was done by descriptive and parametric inferential statistics. The study resulted in important findings about constituents of CPE effectiveness and relevant deterrents impacting $\mathrm{CPE}$ effectiveness. It was for the first time in the Indian scenario that such a study was carried out. Significant group differences were revealed by $\mathrm{T}$ test (gender) and ANOVA (number of years of experience). There were no significant differences amongst the participants in terms of region. Multiple regression analysis revealed that deterrents explained variance in $\mathrm{CPE}$ effectiveness score to the tune of $68 \%$ and it turned out to be substantially high compared to the previous study of similar nature by Wessels [1]. The study presented a model of 'High Quality' or 'Effective' CPE. Recommendations to the Institute of Company Secretaries of India (ICSI) at the conclusion of the study were to prioritize strategies to counter significant deterrents to enhance effectiveness of $\mathrm{CPE}$, evaluate CPE periodically, and improve the quality of CPE. The study was empirical in character and subject to certain limitations. Recommendations for future research include extending this study to other professions, conducting formal audit/evaluation, studying the other constituents that could explain the further variance in CPE effectiveness score, and investigating which of the deterrents are related to each
\end{abstract}

of these individual attributes of effectiveness and to determine how the different aspects of effectiveness are related to each other. In developed economies professional boards started CPE programmes with "The UPDATE MODEL" and moved on to "THE COMPETENCE MODEL" and currently they are focusing on "THE PERFORMANCE MODEL". The objective of CPE at many places has been to promote what is called "Self-directed Learning" going beyond formal education. The ICSI has to understand its limitations in catering to the learning needs of thousands of Company Secretaries.

Keywords Mandatory Continuing Professional Education, Deterrents to Participation in CPE, Evaluation of Mandatory CPE, Effective CPE

\section{Introduction}

The Institute of Company Secretaries of India started Continuing Professional Education (CPE) programmes in the year 2003 and made it mandatory in 2005 for its members to acquire certain number of credit hours as a prerequisite for renewing certificate of practice (COP). Since the inception of CPE programmes during the last ten years, no survey, study, or evaluation was carried to understand the effectiveness of this programme.

Donald Kirkpatrick [2] first published his series of four articles in $\mathrm{T}+\mathrm{D}$ journal about evaluation of training and since then a number of researchers, including Richard Griffin [3], have published research suggesting how organizers of the training programmes should focus on the results of the training and return on investment. The current study has considered the available literature and worked towards creating a scale and research design to measure the effectiveness of the CPE for Indian Company Secretaries.

The purpose of this study is to understand the barriers that may prevent Company Secretaries from participating in 
Continuing Professional Education (CPE). The project also identifies certain factors that make CPE effective and the impact of barriers on effectiveness of mandatory CPE. It is also intended to find out if there exist any differences in perceptions of Company Secretaries about effectiveness of $\mathrm{CPE}$ in terms of gender, region and number of years of experience.

Except for Wessels [1], all previous studies about deterrents to participation were carried out in other countries of the world during the era of voluntary CPE. It would be interesting to see to what an extent same deterrents are applicable to mandatory CPE in the Indian context.

This research contributes to the existing literature on this topic in a number of ways. Company Secretary, which is a unique profession practiced in the United Kingdom and certain Commonwealth countries was surveyed nationwide for the first time. Secondly, it is the first evaluation of mandatory CPE in Indian context. Thirdly, the study provides a model for 'High Quality' or 'Effective CPE' and its components succinctly.

\section{Literature Review}

There is enough research available about the debate on mandatory versus voluntary CPE and both the models (Mandatory and Voluntary) coexist at present. Irrespective of mandatory or voluntary nature of the CPE, currently the worldwide focus is and has to be on making CPE effective for its participants. It has been established beyond doubt that professionals do not merely attend continuing professional education programmes simply because it is made mandatory by their respective boards. There exists a need to find out what motivates them to attend and what barriers exist that prohibit them from participating in such programmes effectively.

\section{Deterrents to Participation in Continuing Professional Education}

Research literature on this topic has termed barriers to participation in continuing education as deterrents. Scanlan [4] defined deterrents to participation as "a reason or group of reasons contributing to an adult's decision not to engage in learning activities" (p. xi).

Pioneering work in this regard was done by Patricia Cross [5] and later expanded by Darkenwald and Merriam [6].
Cross in her landmark book "Adults as Learners" identifies three major categories of barriers to participation (deterrents): Situational deterrents, Institutional deterrents and Dispositional deterrents. Darkenwald and Merriam [6] added a fourth category called Informational deterrents.

Situational deterrents: These are constraints, according to Cross [4], that deal with factors in an individual's life circumstances at a given point in time. The most common of these are not having adequate time and money and having work and family constraints.

Institutional deterrents: These deterrents are those practices, procedures, and policies that place limits on opportunities for potential adult learners to participate. As explained by Cross [4], some of the deterrents identified in the literature till date include quality of CPE programmes, bureaucracy, location of programme, scheduling, relevance and ease of registration.

Dispositional deterrents: These are factors that hinder participation and represent internal barriers based on personal attitudes towards CPE. Cross [4] found that these deterrents relate to attitudes and self-perceptions about oneself as a learner.

Informational deterrents: Darkenwald and Merriam [6] identified these deterrents as barriers to participation relating to a lack of information about the available courses or a lack of information from which to judge the appropriateness of a CPE course.

The focus of this study is to understand the various elements that make CPE effective for the Company Secretaries and which are the deterrents faced by Company Secretaries in the Indian context that result in limiting the effectiveness of CPE. The vital research questions of the present study, therefore, are:

- To what an extent do Company Secretaries in India perceive Mandatory CPE to be effective for them?

- What are the different barriers as perceived by them that bring down the effectiveness of Mandatory CPE for Company Secretaries in India?

- Are there any differences in perceptions of Company Secretaries in terms of Gender, Number of years of Experience and regions (East, South, North and West) of India?

\section{Research Methodology}

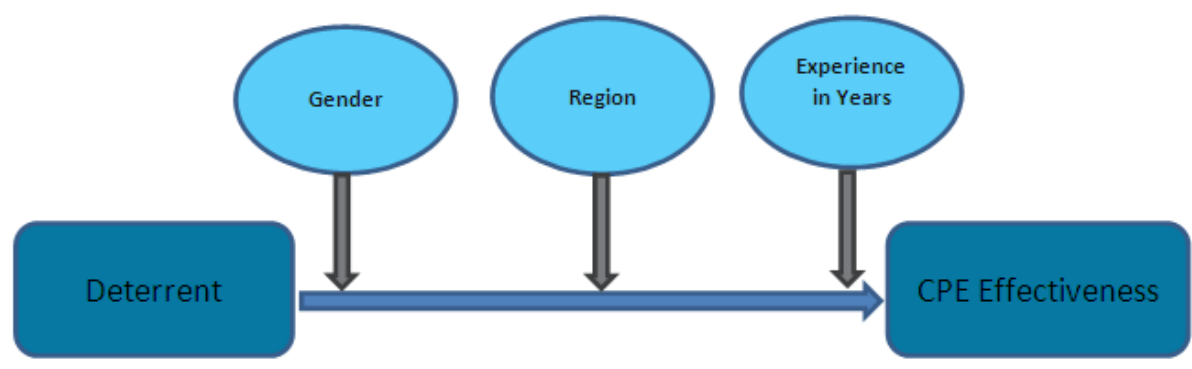

Figure 1. Research Model 
As depicted in the above model, "deterrents" is the independent variable and "CPE Effectiveness" is the dependent variable. The objective is to find out to what an extent deterrents affect the effectiveness of CPE, and also to test whether gender differences, regional differences and number of years of experience have any impact on the effectiveness of CPE.

\section{Development of Survey Instrument}

While preparing the Survey Instrument, out of the four categories of deterrents as established in the research literature and as mentioned above, the category of Informational Deterrents was not considered. This was done because this category is currently not applicable in the Indian context. This fact was also validated during the course of focus group discussions.

In order to develop the Survey instrument a three-step model was followed.

- The website of the ICSI and other sources available providing information about CPE of ICSI were studied,

- A detailed review of literature about various aspects of CPE and effectiveness of CPE as published in international publications including books and research papers was carried out,

- Focus group discussions (FGD) of Company Secretaries were carried out to understand their perceptions about effectiveness of CPE and different barriers faced which reduces their effective engagement in $\mathrm{CPE}$.

Views of participants were recorded during the process of FGDs (two FGDs were carried out) and these views were used to construct the second part of the self-completion survey instrument to gather the perceptions of Company Secretaries about CPE. The first part consisted of demographic and other relevant aspects of CPE. A covering letter was drafted to communicate the purpose of this survey and request the professionals to participate in the same. Post these, steps were taken to establish content and face validity of the instrument and the instrument was shared with the officials of the ICSI and their support was sought to carry the survey in all four regions of the country.

\section{Research Data}

The total number of qualified Company Secretaries was 32,088 (thirty two thousand eighty eight) as per the Annual Report for the year 2012-2013 of the ICSI [7]. Personally administered method was chosen for the data collection, and the survey was carried between July 2013 and November 2013. The survey was done at the beginning or at the end of seminar, lecture or meeting, which was held as a part of ongoing CPE. Total 793 respondents consisted 176 from East Region, 201 from South Region, 208 from North Region and 208 from West Region of India.

\section{Research Findings}

Research findings of this study begin with the table of top 4 items of effectiveness of mandatory CPE which is followed by an analysis of the impact of deterrents on CPE effectiveness.

The following table shows the percent agreement or disagreement and means and standard deviations for each of the fourteen effectiveness items as well as for total CPE effectiveness score.

The top rated item in the above table is "Periodic evaluation would have added to the effectiveness of the program" with a mean value of 4.09 (SD 0.9141). It is noteworthy that the CPE programme in the current format was launched in the year 2003 and has already completed ten years. Till date, the Institute has not conducted any evaluation, nor has it made any attempt to understand views of the members undergoing CPE in any manner. An overwhelming number of 94.70 percentage participants are in favour of periodic evaluation and this finding suggests that the ICSI should address this issue immediately. In addition to evaluation, participants have highly rated items pertaining to benefits of networking, updates from the field, knowledge and improved image of the profession.

Table 1. Descriptive statistics for CPE effectiveness

\begin{tabular}{|c|c|c|c|c|c|c|}
\hline $\begin{array}{c}\text { Item } \\
\text { Number } \\
\text { as per the } \\
\text { scale }\end{array}$ & Effectiveness Item & $\begin{array}{c}\text { Percent- } \\
\text { Strongly agree } \\
\text { or Somewhat } \\
\text { agree or agree }\end{array}$ & $\begin{array}{c}\text { Percent } \\
\text {-strongly } \\
\text { disagree or } \\
\text { disagree }\end{array}$ & $\begin{array}{c}\text { Item } \\
\text { mean }\end{array}$ & SD & $\begin{array}{c}\text { Scale } \\
\text { Rank }\end{array}$ \\
\hline 29 & $\begin{array}{c}\text { Periodic Evaluation would have added to the } \\
\text { effectiveness of the programme }\end{array}$ & 94.70 & 5.30 & 4.09 & 0.9141 & 1 \\
\hline 4 & $\begin{array}{c}\text { CPE courses provided useful networking and } \\
\text { advocacy opportunities with fellow } \\
\text { professionals }\end{array}$ & 94.58 & 5.42 & 3.85 & 0.8605 & 2 \\
\hline 6 & $\begin{array}{c}\text { CPE courses provided me excellent contacts } \\
\text { with experts }\end{array}$ & 87.52 & 12.48 & 3.63 & 1.0079 & 3 \\
\hline 2 & $\begin{array}{c}\text { CPE courses provided me a useful opportunity of } \\
\text { updating latest development in my field }\end{array}$ & 87.52 & 12.48 & 3.63 & 1.0499 & 4 \\
\hline
\end{tabular}


Table 2. Multiple regression analysis of deterrent items on CPE Effectiveness

\begin{tabular}{|c|c|c|c|c|}
\hline Item & Deterrents & Beta & $t$ & $P$ \\
\hline & Institutional deterrents & & & \\
\hline 15 & There was a scope to reduce the required number of $\mathrm{CPE}$ hours & -0.047 & -3.10 & 0.002 \\
\hline 24 (Reverse coded) & CPE courses were very relevant to my practice/employment area & -0.174 & -10.01 & $<.0001$ \\
\hline \multirow[t]{2}{*}{26 (Reverse coded) } & I found CPE courses of high quality & -0.199 & -11.81 & $<.0001$ \\
\hline & Dispositional deterrents & & & \\
\hline 1 (Reverse coded) & $\begin{array}{l}\text { I did not get enough opportunities to update my knowledge other } \\
\text { than CPE courses }\end{array}$ & -0.053 & -4.27 & $<.0001$ \\
\hline 7 & CPE courses were not meant for networking/advocacy & -0.029 & -2.66 & 0.008 \\
\hline 9 & $\begin{array}{l}\text { I was unable to apply learning from CPE courses to solve my on the } \\
\text { job problems }\end{array}$ & -0.008 & -0.52 & 0.6051 \\
\hline 12 & I did not like class room lectures & -0.012 & -0.92 & 0.3587 \\
\hline 14 & $\begin{array}{l}\text { If the CPE courses were not mandatory I would have taken fewer } \\
\text { CPE courses }\end{array}$ & -0.008 & -0.53 & 0.5929 \\
\hline 16 & As I gained more experience I find less utility of CPE courses & -0.005 & -0.34 & 0.7319 \\
\hline 10 & Mandatory CPE did not necessarily result in learning & -0.036 & -2.49 & 0.0128 \\
\hline 11 (Reverse coded) & $\begin{array}{l}\text { In the absence of mandatory CPE I might not have made efforts } \\
\text { towards updating my knowledge }\end{array}$ & -0.024 & -2.00 & 0.0463 \\
\hline 13 & $\begin{array}{c}\text { Mandatory CPE was more useful only during the early years of } \\
\text { practice/employment }\end{array}$ & 0.008 & 0.55 & 0.5794 \\
\hline \multirow[t]{2}{*}{27} & I attended CPE courses only to fulfil my credit hours' requirement & -0.063 & -4.05 & $<.0001$ \\
\hline & Situational deterrents & & & \\
\hline 8 & CPE courses left less time for my family and friends & -0.006 & -0.42 & 0.6779 \\
\hline 28 & The demands of my practice/job left little time for CPE courses & -0.023 & -1.53 & 0.1262 \\
\hline
\end{tabular}

\section{Impact of Deterrents to Participation on CPE Effectiveness}

Multiple regression analysis of deterrent items on $\mathrm{CPE}$ effectiveness as per Table-2 showed impact of each of the deterrents on CPE effectiveness. Analysis was conducted using the fifteen deterrents items on the survey as independent variables and CPE Effectiveness score as the dependent variable. Each of the fifteen survey items was scored by the participants with a 5 for 'strongly agree', 4 for 'agree', 3 for 'somewhat agree', 2 for 'disagree' and 1 for 'strongly disagree'. Item number 1, 11, 24 and 26 were reverse scored (so that 5 became 'strongly disagree' and 1 became 'strongly agree').

The model showed that the interaction of the fifteen deterrents explained $68 \%$ of the variance in the $\mathrm{CPE}$ effectiveness score $(\mathrm{R} 2=06853$; R2 $\mathrm{adj}=0.6793)$. Items related to opportunities to update knowledge other than $\mathrm{CPE}$, scope to reduce stipulated number of CPE hours, relevance to practice/employment, mandatory attendance, and not having high quality were significantly impacting $\mathrm{CPE}$ effectiveness.

\section{Discussion}

This study resulted in identifying what makes CPE effective for Company Secretaries and which are the factors that bring down the effectiveness, called as deterrents. Deterrents pertaining to item number 1 and 11 are linked to each other and the responses by survey participants have two important implications.

1. Majority of Company Secretaries (over seventy percent) feel they are capable of taking care of their own learning or they have what is called 'Self-Directed Learning' orientation. Also, they perceive that there are adequate opportunities for them to update their knowledge and they were not dependent upon mandatory CPE for the same.

2. Mandatory CPE has scope to find out exactly what professionals are seeking that ICSI could include in lectures, seminars, and various professional development programmes to make professionals attitude more favourable towards mandatory CPE.

Sixty seven percent participants were of the opinion that CPE was not of high quality (Table 2, item 26). What are the elements of High Quality or Effective CPE? Based on the extensive review of literature, personal discussion with some of the professionals, and reflections on this subject matter, this researcher has arrived at the following model shown in figure 2 . 


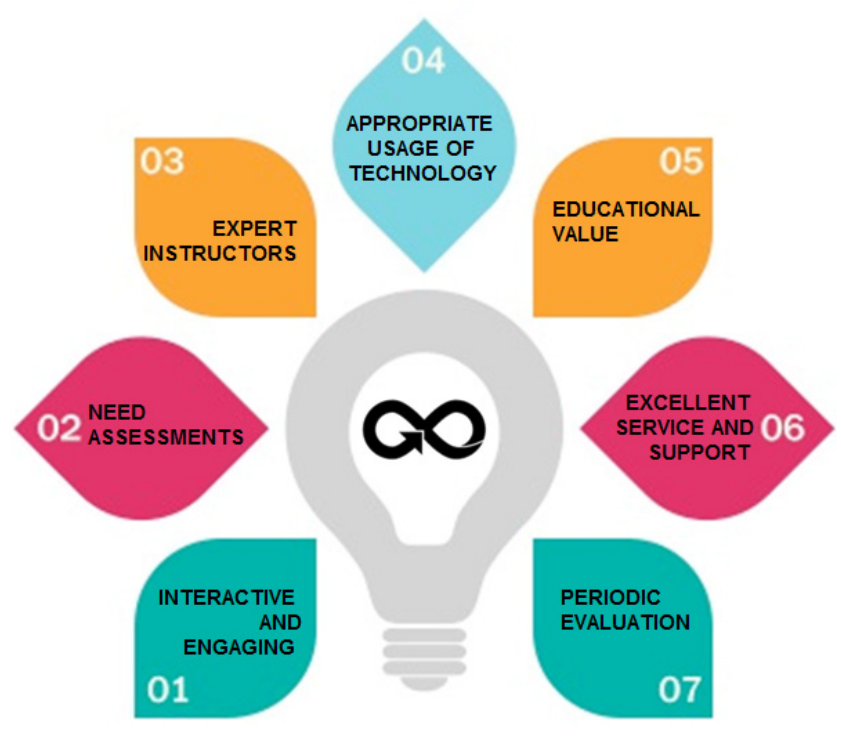

Figure 2. Effective CPE

1. Interactive and engaging content that covers topics that is timely and relevant.

2. Such topics should have basis in the "need assessments" conducted from time to time.

3. Expert instructors, with years of deep experience in the profession, who can translate concepts into insights that participants can apply wherever required.

4. Effective learning methods inclusive of, but not restricted to, class room lectures, and appropriate usage of technology going beyond standard power point slides, have to be employed.

5. Efficient as well as effective learning that gives participants the most educational value for their time and other resources.

6. Excellent service and support, before, during and after the course to make sure that the participants are completely satisfied and that they have the critical information they may need to further their career.

7. Periodic evaluation of the $\mathrm{CPE}$ should lead to continuing improvement in features and quality of the programmes.

This researcher is of the opinion that while following the above mentioned model, organizers of CPE could enhance the effectiveness of CPE and reduce the impact of deterrents significantly.

\section{Limitations and Scope for Future Research}

The study was empirical in character and subject to certain limitations. The researcher concentrated only on the profession of Company Secretaries. By replicating this study for other similar professions, a greater understanding may be gained. This study resulted in an evaluation of CPE for Company Secretaries in the tenth year from its inception, in a limited sense. This resulted in assessment long after some of the events.

The chosen set of fifteen deterrents explained variance to the tune of $68 \%$ in the CPE effectiveness score. Efforts are required on the part of future researchers to understand what are the other constituents that could explain the further variance in CPE effectiveness score.

In the present study, effectiveness was measured using a scale consisting of fourteen different attributes. Additional research is recommended to investigate which of the deterrents are related to each of these individual attributes of effectiveness and to determine how the different aspects of effectiveness are related to each other.

\section{Conclusions and Recommendations for Further Action}

The first part of the Survey Instrument carried a section for participants' suggestions for enhancing/ improving CPE. Out of 793 participants, 115 participants made good use of this space and offered a good number of suggestions to counter some of the deterrents and enhance effectiveness of CPE. Many of the suggestions validated inferences of the study.

This exploratory study is the first in India examining the relative importance of deterrents to participation in settings in which participation is mandatory. In this study of deterrents to participation and their impact on reducing CPE effectiveness, we have come to know what is applicable in this country. Some of the deterrents from the previous studies (when CPE was voluntary) still have significant impact even as CPE was being made mandatory. As steps will be taken to counter the identified deterrents, we are likely to face new sets of deterrents. Hence, such studies have to be conducted on ongoing basis with the gap of a certain period. The implications are not just restricted to CPE of Company Secretaries. They could be extended to other professions where CPE is mandatory. This study could have an important contribution towards theory of evaluation as well.

The study shows the exact areas wherein the ICSI could focus to improve upon the effectiveness of CPE and bring down the impact of the deterrents on effectiveness of CPE. Based on the distinct findings ICSI could decide the priority for policy measures to be taken in time to come. Periodic evaluation, enhancing the quality of CPE, reducing the stress on classroom lectures, introduction of technology for conducting CPE and moving on from 'UPDATE' model of CPE to 'COMPETENCE' and eventually to 'PERFORMANCE' model of CPE as propounded by Nowlen [8], should be the immediate focus areas for the ICSI.

\section{This research leads to following suggestions to different stakeholders}

Finding about CPE effectiveness and items where the scoring is low should result in creating agenda for ICSI educators so that CPE effectiveness enhances in time to 
come.

Finding about deterrents and their significant impact on CPE effectiveness should result in creation of a plan to counter those deterrents and enhance CPE effectiveness.

ICSI should create a plan for periodic evaluation as demanded by its members.

There were no significant regional group differences and this could be a good news for ICSI as they could create a strategy which fits the entire country and they need not go to the trouble of addressing different zones of India.

Group differences were significant for gender and groups based on number of years' of experience. Further probe is needed to understand the concerns of female professionals and while organizing programmes segmentations should be done based on number of years' of experience.

Other professional boards such as ICAI and $\mathrm{ICAI}_{2}$ could make use of this report for enhancing their own CPE effectiveness.

Learning and Development professionals could work on these issues, particularly on the effectiveness of training and learning and development programmes organized by employers. This may not be the same as CPE, but the techniques for measurement of effectiveness and the vast number of serious problems facing those who attempt to measure effectiveness are similar.

\section{REFERENCES}

[1] Wessels, S. B. Accountants' Perceptions of the Efectiveness of Mandatory Continuing Professional Education, Accounting Education, 16(4), 365-78, 2007.

[2] Kirkpatrick, D. L. Evaluating training programs: the four levels. San Francisco, CA: Barrett- Koehler, 1998.

[3] Griffin, R. Complete training evaluation: the comprehensive guide to measuring return on investment. London: Kogan Press Limited, 2014

[4] Scanlan, C. L. Detterrents to particiaption: An adult education dilemma. Columbus: ERIC Clearinghouse on Adult, Career, and Vocational Education, The Ohio State University, 1986.

[5] Cross, K. P. Adults as learners. California, San Frasisco, U S A: Jossey-Bass, 1981.

[6] Darkenwald, G. G. and Merriam, S. B. Adult education: Foundations of practice. New York: Harper and Row, 1982.

[7] 33 ANNUAL REPORT 2012-13 Regulating and Developing the Profession of Company Secretaries, Online available from http://www.icsi.edu/WebModules/Linksofweeks/AR2012-13 .pdf, 2013.

[8] Nowlen, P. M. A New Approach to Continuing Education for Business and the Professions The Performance Model. New York: Macmillan Publishing Company, 1988. 